\title{
Interpretation of CBR Test Results Based on the Rapid Impact Compaction Electro-Mechanic System Model
}

\author{
Arifin Beddu ${ }^{1,}{ }^{*}$, Lawalenna Samang ${ }^{1}$, Tri Harianto ${ }^{1}$, and Achmad Bakri Muhiddin ${ }^{1}$ \\ ${ }^{1}$ Civil Engineering Department, Hasanuddin University, Indonesia
}

\begin{abstract}
In order to understand the mechanical properties of the compaction results and to optimize the relevant energy design of the repeated Rapid Impact Compaction (RIC), a series of California Bearing Ratio (CBR) tests were performed on the compaction sample with RIC electro-mechanic system. In this laboratory test, samples were compacted at various RIC impact energy levels. A mass of different weight and various of falling height was used to compact the samples in a CBR cylindrical test. The mass was repeatedly dropped on the anvil plate with a frequency of 30-40 blows per minute. The compaction process carried out by varying number of blows from 5 to 35 for each compacted sample, and all compaction processes were controlled by electro-mechanic new development system. The test results represented that there was a variation of CBR value at the same RIC energy levels. The CBR values at the same energy level with the larger number of blow increased higher in lighter mass, whereas than the RIC energy level for larger masses with the smaller number of blows also occurred with the same trend to the result of relative compaction density test. This advantages that with a better understanding of RIC mechanisms and relevant energy designs, it is a new practical idea to improve compaction degree as well as CBR value on fill construction works with appropriate equipment and lower energy consumption.
\end{abstract}

\section{Introduction}

The requirement of earthwork for infrastructure in some Asian countries increased significantly during the last of two decades, due to the rapid development such as in the field of highways, railways, airports, and ports. The increasing needs for adequate earthwork for construction have pushed the need for the use of appropriate and economical ground improvement techniques. One method widely used to stabilize the mechanical properties of the soil is a method of impulses repeated densification by Rapid Impact Compaction (RIC) [1-4]. This method has been developed and used widely because it offers practical and economical technology with the concept of low energy dynamic compaction [5].

\footnotetext{
*Corresponding author: arifin_beddu@yahoo.com
} 
On the other hand, in the practice of earthwork preparation's construction that requires compaction is always associated with the method of proctor test as well as California Bearing Ratio (CBR) as the main method of assessment parameters the results of compaction [6-7]. Therefore, CBR test is an important component for the design of earthwork preparation's especially in the pavement structure for both flexible and rigid pavements. The CBR test can be done either in the laboratory for designing or in situ for the evaluation of compaction results [7]. However, because it takes time to get the result and cannot be easily determined in the field, the prediction and interpretation of the correlation of CBR considered being the most logical and simple [8].

Due to the reasons as mentioned earlier and since the use of RIC compaction system been widely used, it is possible to conduct research that focuses on the control of compaction results, especially the characteristics of the CBR value on the construction of embankment compacted using rapid impact compaction method. In this research, a mass of different weight and falling height was used to compact the sample in a CBR cylindrical mould test. The mass was repeatedly dropped on the anvil plate with frequency 30-40 blows per minute, and the compaction process was carried out by varying number of blows from 5 to 35 for each compacted sample, all compaction processes were controlled by electromechanical new development system and performed in the laboratory.

\section{Literature review}

\subsection{Compaction Energy}

A general relationship between moisture content, density, and compaction energy can be predicted from the results of a compaction curve. In a compaction process, increasing water content will relatively change the structure of the soil easily, and the dry density will increase along with the compaction efforts. However, if the dry density plotted against the water content for the same effort, will be obtained that the dry density can reach the peak, then after that, any increase in water content will further produce a dry density lower.

There are two main parameters obtained from the curve of compaction; maximum dry density and optimum moisture content [9]. Improving the compaction effort will increase the maximum dry density but reduces the optimum moisture content. On the compaction curve it was found that the ratio of air voids remains the same at maximum density, but at the high moisture content, there was only a slight increase in the density which obtained by increasing the compaction effort. In this case, the compaction energy per unit volume $(E)$ used as shown in Equation. (1) for the Proctor test is determined by the number of blow each layer $(N)$; number of layers per mould $(l)$; the weight of the compactor $(W)$ and the falling height of the compactor $(h)$ the the mould volume [10].

$$
E=\frac{(N) \cdot(l) \cdot(W) \cdot(h)}{V} \quad\left(\mathrm{kN}-\mathrm{m} / \mathrm{m}^{3}\right)
$$

\subsection{California Bearing Ratio}

The California Bearing Ratio, CBR is expressed as the percentage ratio of unit force $(P)$ that has to be applied so that a standardized circular piston may be pressed to penetrate 2,5 $\mathrm{mm}$ and $5 \mathrm{~mm}$ into a soil specimen at a rate of $1.27 \mathrm{~mm} / \mathrm{min}$ to standard force (Ps) corresponding the unit force necessary to press the piston at the same rate into the same depth of a standard compacted crushed rock as shown on the following Equation (2), [11]. 


$$
C B R=\frac{P}{P_{S}} .100 \%
$$

At present, the value of the CBR has been used as a method to evaluate the quality of the assessment of the earthwork for subgrade layers or sub-base. It has been applied extensively to test material ground and granular in the laboratory for more than seventy years [7]. The value of CBR is closely associated with the characteristics of compaction, such as the moisture content, dry weight, energy conditions and the method of compaction [7]. Compacted soil with a moisture content higher than optimum moisture content will have lower CBR value. Immersion of the specimen causes a decrease in the value of CBR. This condition will be quite significant in the specimens compacted at dry of optimum but will be less significant at optimum water content. The CBR value will be lower on the samples which are compacted at optimum wet but will be higher when the applied energy increased [9].

\subsection{Rapid impact compaction}

The Equipment of Rapid Impact Compaction, RIC consists of main components such as foot compactor (anvil) and a compactor (hammer) [12-13]. On the method of rapid impact compaction, the hammer was dropped on an anvil which placed above the surface of the soil in the mould. The frequency of the blows was $30-40 / \mathrm{min}$ as a characteristic of the method of rapid compaction [8]. The amount of energy the RIC was very small compared to the method of DC conventional, nevertheless the emphasis the more important thing was the number of blow at the point of compaction so that the overall total energy of RIC produced a very big influence on the effective depth of compaction results [14].

The energy compaction parameters of RIC method was influenced by the weight of the hammer; the weight and area of the anvil; the frequency of blows and the cumulative compaction energy at the same impact point. The compaction energy was focused on the magnitude of the weight of the hammer, and the number of impact blows. This was appropriate with the results of the research [15] that in the method of impact compaction effect of the weight of the compactor was significant compared to the falling height. The effect of the increasing weight of the compactor on compaction impact to depth can be explained by the effect of the increasing momentum on the efficiency of the energy transferred to the soil layer [15].

\section{Research Methodology}

The research consisted of laboratory testing and analysis of results. Thus, it is important to have a testing program, instrumentation and the sequence of actions. The data used for this research was the primary data gathered from primary sources and obtained by performing laboratory test which following test procedure as described.

\subsection{Material testing}

The soil samples are classified as (ML) according to the classification system soil of USCS, the maximum dry density of $14.1 \mathrm{kN} / \mathrm{m}^{3}$ at the optimum moisture content of $28.04 \%$ with Proctor standard test. The CBR unsoaked $16.97 \%$ at the optimum moisture content and maximum dry weight density by standard Proctor testing. The physical and mechanical 
properties of the soil are summarized in Table 1. while the grain size distribution can be shown in Figure 1.

Table 1. Physical and mechanical properties of the materials

\begin{tabular}{|l|c|}
\hline Properties & Values \\
\hline Wet density, $\left(\mathrm{kN} / \mathrm{m}^{3}\right)$ & 10.3 \\
Water content $(\%)$ & 38.36 \\
Specific gravity & 2.73 \\
Liquid Limit, (\%) & 55.89 \\
Plastic limit, (\%) & 47.48 \\
Plasticity index (\%) & 8.41 \\
Maximum dry density, $\left(\mathrm{kN} / \mathrm{m}^{3}\right)$ & 14.1 \\
Optimum water content, $(\%)$ & 28.04 \\
CBR unsoaked (\%) & 16.97 \\
\hline
\end{tabular}

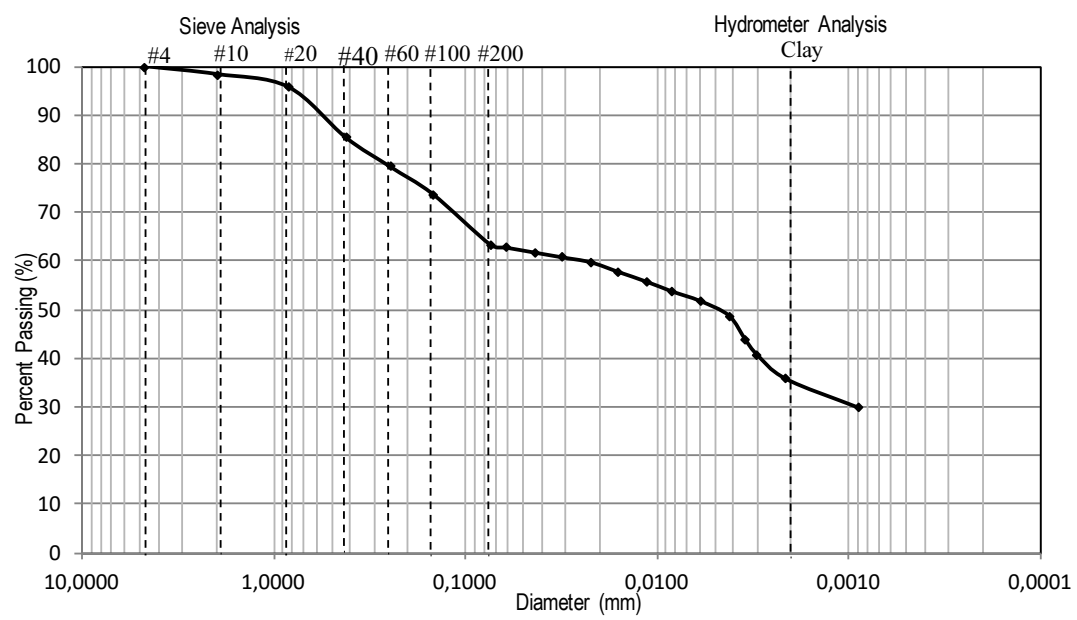

Fig. 1. Grain size distribution.

\subsection{Apparatus of RIC}

In this experimental test, the equipment of repeated load impact used an air-pneumatic piston. The main components of the equipment consisted of air compressor, piston doubleacting air pneumatic-pressure, valve solenoid, panel controller and mass compactor as shown in Figure 2. Repeated load impact equipment has $1.50 \mathrm{kN}$ vertical lift capacity of the mass compactor and falling height can be set $10 \mathrm{~cm}$ to $30 \mathrm{~cm}$, the period of the impact compaction is being 2-3 seconds per blow. For testing stability, the apparatus was attached and positioned on a steel frame. The weight of the mass compactor was used by $0.45 \mathrm{kN}$ and $0.70 \mathrm{kN}$ of steel blocks. 


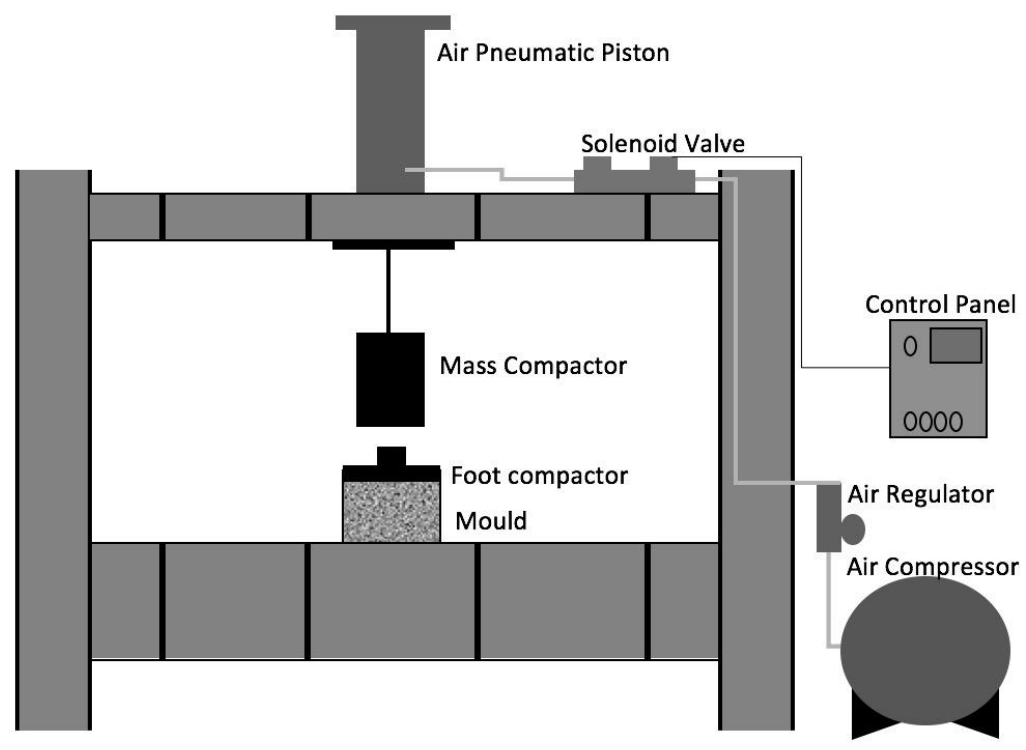

Fig. 2. Schematic of model equipment of electro-mechanic system rapid impact compaction model.

\subsection{The CBR moulds}

For testing, the property of mould used was the inner diameter of $15 \mathrm{~cm}, 25 \mathrm{~cm}$ in height, the volume of the mould $0.0044 \mathrm{~m}^{3}$. For the compacting process, the mould was equipped with a pedestal pad as foot compactor or anvil which has adjusted size to the diameter of the mould. The anvil was a steel plate which has $2 \mathrm{~cm}$ of thickness; the rod connection was $15 \mathrm{~cm}$ in height and diameter of $7.5 \mathrm{~cm}$.

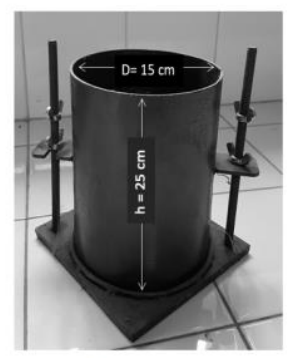

a.

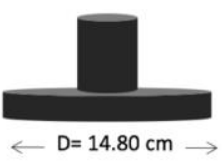

b.

Fig. 3. Compaction apparatus test: a. Cylindrical mould test; b. Anvil

\subsection{Sample preparation}

The soil in the compaction mould was obtained from the remoulded CBR sample, the required amount of soil was mixed with water and left under a plastic for air drying to obtain a water content in accordance with the standard proctor compaction of $26-28 \%$ and $0.046 \mathrm{kN}$ of soil was filled in the compaction mould without compacting by controlling the loose density of $10.4 \mathrm{kN} / \mathrm{m}^{3}$. 


\subsection{The RIC process}

The compaction process with rapid impact compaction was performed using various energy levels by applying the various impact blow. The square-shaped mass compactor with 0.45 $\mathrm{kN}$ and $0.70 \mathrm{kN}$ in weights were used in this test, and adjustable falling height was set at 15 $\mathrm{cm}, 20 \mathrm{~cm}$ and $25 \mathrm{~cm}$ for each sample tested. In the compaction process, the mass of compactor was periodically dropped over the anvil with ranging of frequency 30-40 blows per minute, the impact process being carried out by varying blow ranging from 5 to 35 amount of the blows for each mould compaction. In this research, all compaction process was controlled by a new developed electro-mechanic system of rapid impact compaction.

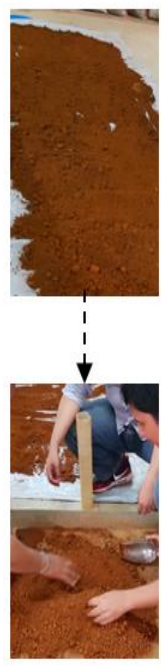

a

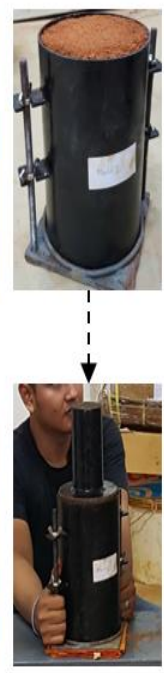

b

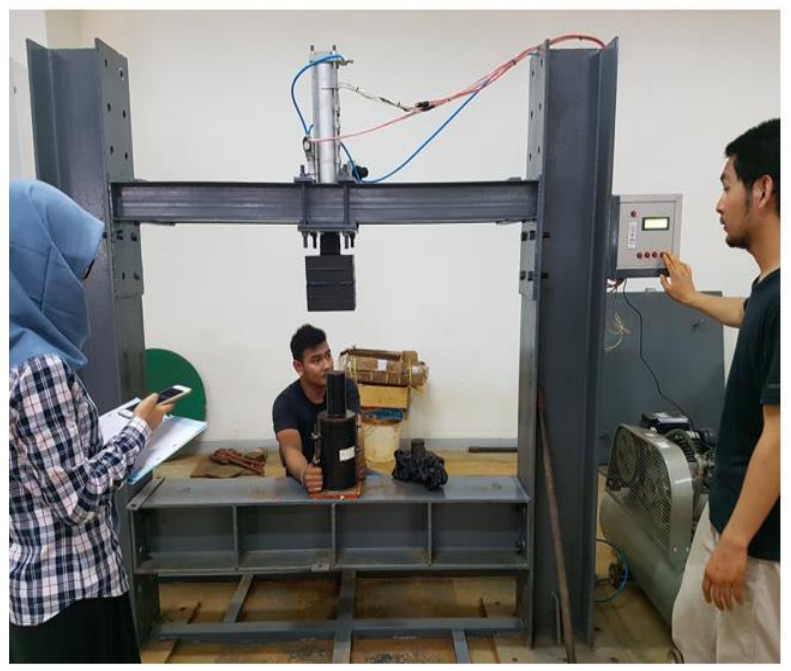

C

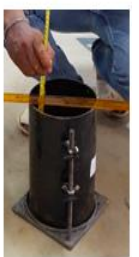

d

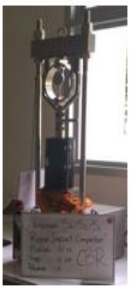

e

Fig. 4. Program of testing: a. Sample preparation; b. Set up of the anvil; c. Compaction proses; d. Measurement of final settlement; e. CBR testing.

\subsection{The CBR test}

As soon as the rapid impact compaction has been applied, the next step was the CBR testing which conducted at the optimum water content in accordance with the target sample on the mould test. The CBR test consisted of a metal penetration piston with a diameter of $50 \mathrm{~mm}$ and a length of $100 \mathrm{~mm}$, and with $5000 \mathrm{~kg}$ of maximum load capacity were used which equipped by a moving head or base at a uniform level of $1,27 \mathrm{~mm} / \mathrm{min}$. The CBR value was calculated for penetration of $2.5 \mathrm{~mm}$ and $5 \mathrm{~mm}$. After completed the CBR test, the water content of the samples was re-examined.

\section{Result and discussion}

During the test, the CBR value corresponding to the number of impact blow, cumulative energy and the effect of falling height were obtained, recorded and analyzed. It is intended to be able for the presence of a set of results from this study to observe the effect of various variables in the soil CBR values in the mould compaction. The determination of the CBR value to correction of the water content, the size of the mould and the pressure of the load surcharge in order to test the rapid impact compaction was not yet implemented. 


\subsection{Effect of RIC blow number on CBR}

Variation number of blow between 5 to 35 blows in the observations to develop a relationship with the acquirement of the maximum value of CBR. Figure. 5 shows that until of the 15 blows, there is no significantly effect of blow number to the CBR value which only $40 \%-60 \%$ of the highest value at maximum compaction, but after of 25 to 35 blows, it can be seen that the achievement of CBR value are greater than $80 \%$ for all levels of the energy which are given, this indicates that number of blow will be the dominant effect, although the mass and the falling height are different.

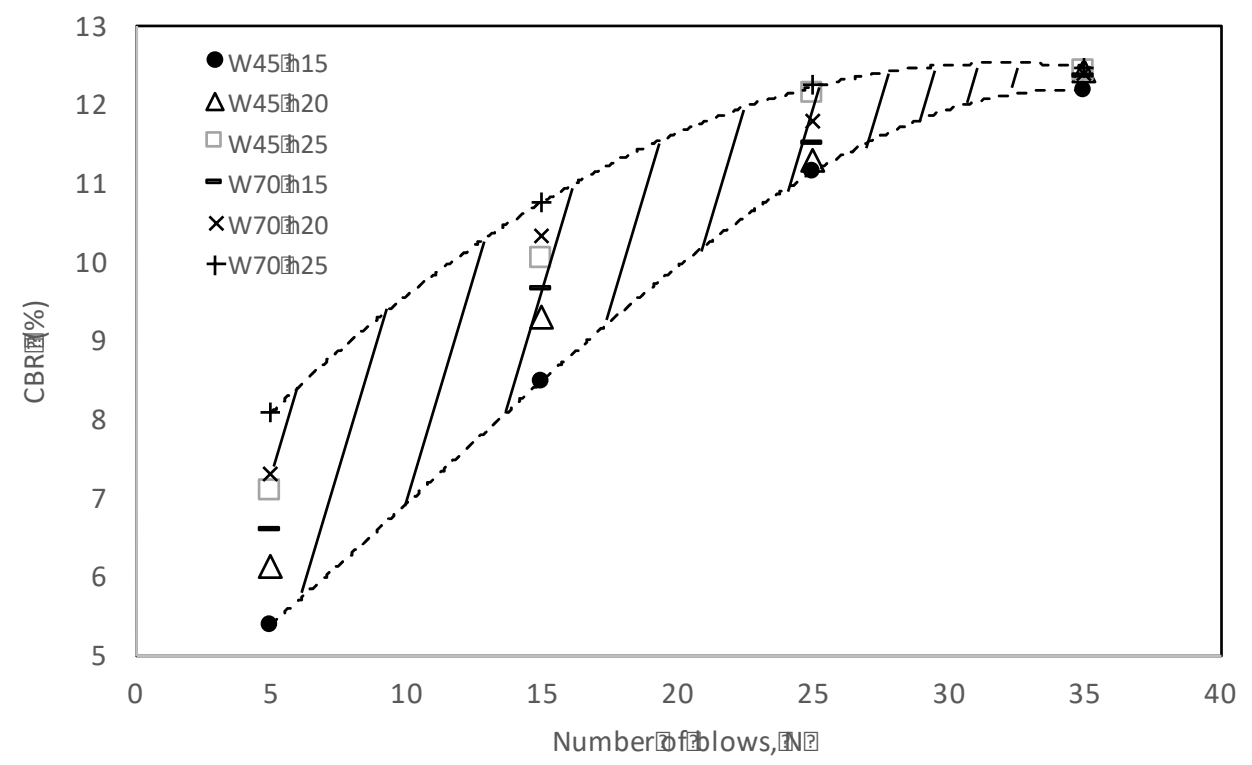

Fig. 5. Number of blows versus $C B R$ values

Based on the test result at 35 blows, CBR design value of RIC system indicates insignificant variations, although, the mass and falling height of compactor were varied. Thus, an interpretation of the CBR design has been considered at 35 number of blows. Therefore, the relation between correction factor and standard CBR design can be presented mathematically with the following Equation (3).

$$
\mathrm{CBR}_{\mathrm{Lab}}=\mathrm{FC} \cdot \mathrm{CBR}_{\mathrm{RIC}}
$$

Where, FC value for this test was 1.36 to 1.39

\subsection{Effect of RIC cumulative energy on CBR}

Generally, the CBR value obtained will increase with the increasing of cumulative energy, Figure. 6 shows the relationship between CBR values and cumulative energy which are divided into three groups of energy level that is preliminary, intermediate and advanced energy zone, respectively.

At the preliminary level, the difference between the mass of the compactor with each other is clearly visible to the value of CBR, in this zone the change of the mass of the compactor and the falling height will make a significant effect, while, in the intermediate zone, the effect of the difference between of the mass of compactor and the falling height 
has shown to decrease which is more determined by the number of blows of energy cumulative. Furthermore, the difference between masses of compactor and falling height did not clearly appear on the specimens which compacted with high energy levels in the advanced zone. This caused by the attainment of CBR value has been achieved in the cumulative energy, hence every additional of energy by adding the weight of compactor mass, falling height and the number of blows will not be significantly different and effect anymore.

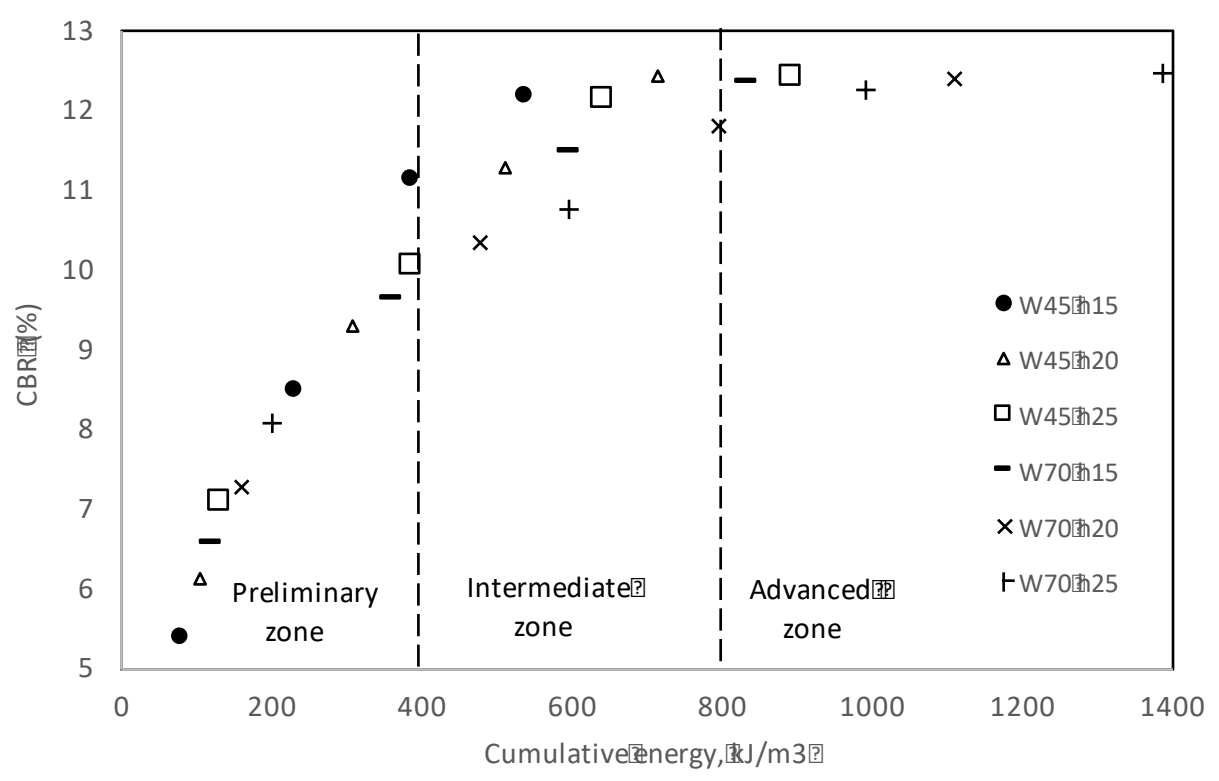

Fig. 6. Cumulative energy versus $\mathrm{CBR}$ values

\subsection{Effect of RIC falling height on CBR}

The analysis was performed on each of the falling height of $15 \mathrm{~cm}$ and $25 \mathrm{~cm}$ for each mass compactor of W45 and W70 as shown in Figure. 7 and Figure. 8. A difference in the achievement of CBR by W45 was $31 \%, 18 \%$, and $9 \%$ while for the W70 by $22 \%, 11 \%$, and $6 \%$ respectively for the number of blows 5,15 and 25 . Based on this result, it can be shown that for smaller masses of the compactor, changing in falling height gave the difference in the achievement of larger CBR value than to the larger mass of the compactor. This indicates that the falling height will be more influent than the mass of compactor on the difference in the achievement of the CBR value. 


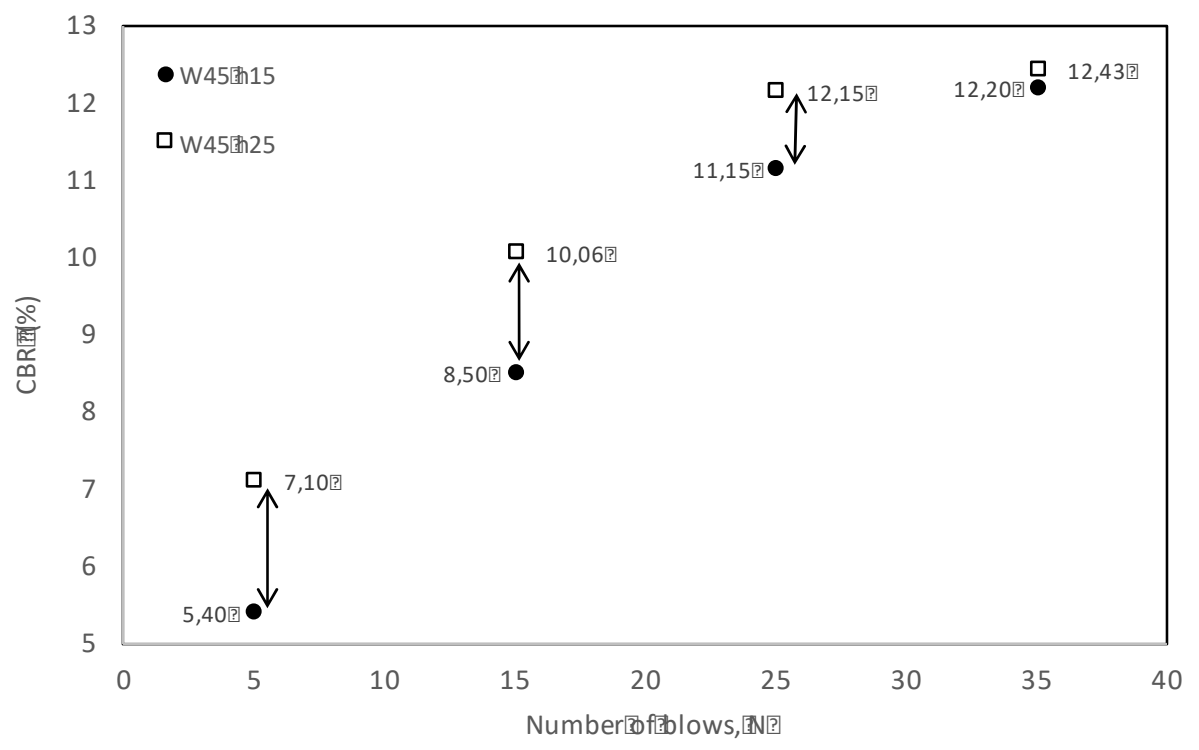

Fig. 7. Falling height at W45 versus CBR values.

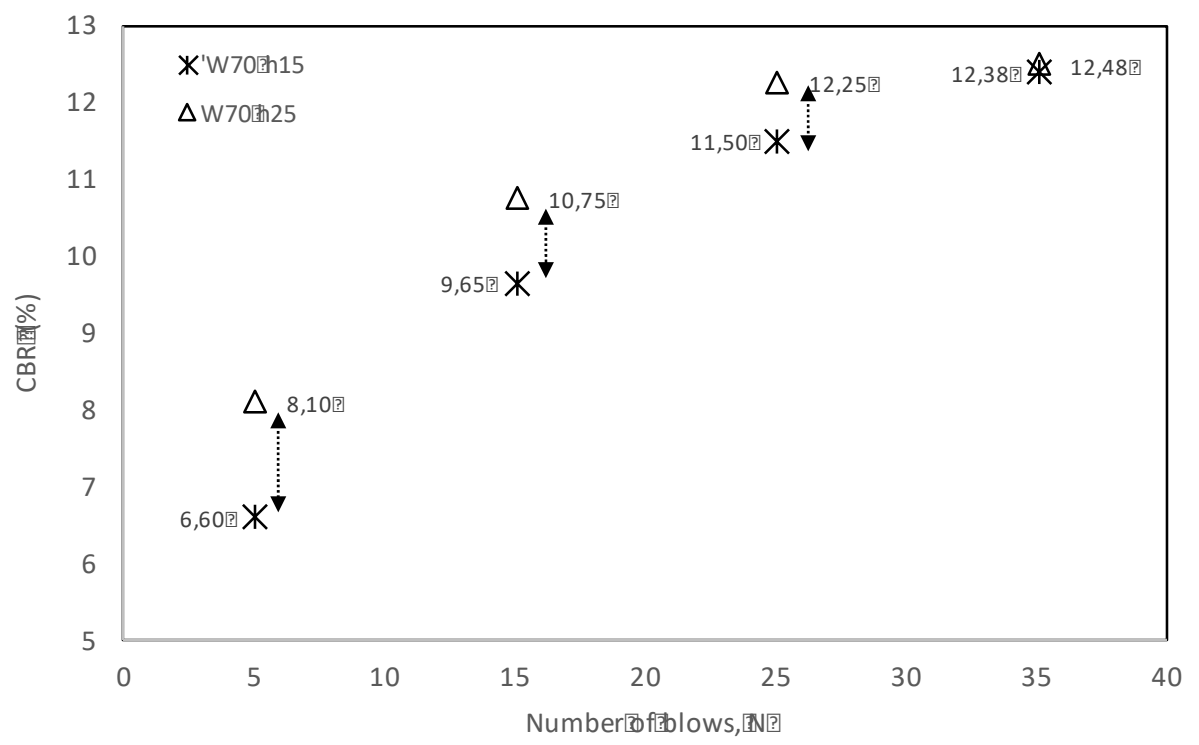

Fig. 8. Falling height at W75 versus CBR values.

\section{Conclusions}

Based on the result of CBR value was obtained from of the rapid impact compaction, indicating that the effect of the number of blows will be dominant to the achievement of CBR values, especially for CBR which has value greater than $80 \%$ of the maximum value, in case for all energy levels that is given although the mass and the falling height are different, on the otherwise the achievement of CBR value which is less than $60 \%$ the 
number of blows is not significant difference, so that in this condition the mass and the magnitude of falling height which will be more dominant.

Energy level distribution patterns can be divided into three zones are preliminary intermediate and advanced, respectively. The implication of each of these zones is that if we are going to work on preliminary zones then the weight of mass of compactor and falling height should be considered, while at the energy level of the intermediate zone the effect of compactor mass and falling heights will have more influence for achieving the maximum CBR value, next in the advanced zone the weight of the compactor and the falling heights are no longer a real differentiator for achieving the maximum CBR value.

The deviation ranges achievement of CBR value will be greater in the change of falling height at the smaller mass of compactor than the larger mass, although the CBR value achieved remain larger is still larger, this indicates that the falling height will not influence the mass compactor to the difference in the achievement of the CBR value.

\section{References}

1. E. Ghanbari and A. Hamidi, "Numerical modelling of rapid impact compaction in loose sands," Geomechanics and Engineering., Vol. 6, no. 5, pp. 487-502, (2014) sép:

2. V. Vukadin, "The improvement of the loosely deposited sands and silts with the Rapid Impact Compaction technique on Brezice test sites," Engineering Geology, Vol. 160, pp. 69-80, (2013).

3. B. Tarawneh and M. Matraji, "Ground improvement using rapid impact compaction: case study in Dubai," Journal of the Croatian Association of Civil Engineers, Vol. 66, pp. 1007-1014, (2014).

4. H. Pankrath, M. Barthel, A. Knut, M. Bracciale, and R. Thiele, "Dynamic soil compaction-recent methods and research tools for innovative heavy equipment approaches," Procedia Engineering, Vol. 125, pp. 390-396, (2015)

5. M. Parvizi, "Soil response to surface impact loads during low energy dynamic compaction,” Journal of Applied Sciences, Vol. 9, no. 11, pp. 2088-2096, (2009).

6. H. Yusuf, M. S. Pallu, L. Samang, and M. W. Tjaronge, "Characteristical Analysis of Unconfined Compressive Strength and CBR Laboratory on Dredging Sediment Stabilized With Portland Cement," International Journal of Civil \& Environmental Engineering IJCEE-IJENS, Vol. 12, no. 4, (2012).

7. K. Zabielska-Adamska and M. J. Sulewska, "Dynamic CBR Test to Assess the Soil Compaction,"Journal of Testing and Evaluation, Vol. 43, no. 5, pp. 1028-1036, (2015).

8. F. Falkner, C. Adam, I. Paulmichl, D. Adam, and J. Fürpass, "Rapid Impact for Middle-Deep Improvement of the Ground - Numerical and Experimental Investigations," From Research to Design in European Practice, June, pp. 2-11, (2010).

9. C. Rajasekhar, A. Naga Sai Baba, and M. Kameswara Rao, "To Develop a Correlation Between CBR and Dynamic Cone Penetration Value," International Journal For Technological Research In Engineering, Vol. 4, no. 1, pp. 11-16, (2016).

10. B. M. Das, "Principles of Geotechnical Engineering," 7 th. Cengage Learning 200 First Stamford Place, Suite 400 Stamford, CT 06902 USA, (2010). 
11. ASTM D1883-16, "Standard Test Method for California Bearing Ratio (CBR) of Laboratory-Compacted Soils, ASTM International, West Conshohocken, PA,” (2016).

12. H. Kristiansen and M. Davies, "Ground Improvement Using Rapid Impact Compaction," 13th World Conference on Earthquake Engineering, August 2004, pp. $1-10,(2004)$.

13. M. M. Mohammed, R. Hashim, and A. F. Salman, "Effective improvement depth for ground treated with rapid impact compaction," Scientific Research and Essays, Vol. 5, no. 18, pp. 2686-2693, (2010).

14. C. J. Serridge and O. Synac, "Application of the Rapid Impact Compaction (RIC) technique for risk mitigation in problematic soils," IAEG2006, no. 294, pp. 1-13, (2006).

15. Koohsaria. H, Alielahia.H, Najafib.A, Adampira.M, "Evaluation of factors affecting the estimated improvement depth of dynamic compaction using fuzzy method and PSO,” J. Soils Found. 2016, Japanese Geotech. Soc, (2016). 